Proceedings

\title{
Synergies and trade-offs in ecosystem services' provision in Sar- dinia (Italy): A planning-oriented spatial assessment.
}

Sabrina Lai*

* Department of Civil and Environmental Engineering, and Architecture. University of Cagliari, Italy; sabrinalai@unica.it

\begin{abstract}
Multifunctionality, i.e. nature's capacity to deliver multiple ecosystem services (ESs), is a key component of a green infrastructure. Investigating multifunctionality through a structured model, grounded on spatial statistics and applied to spatial data on ES provision, can therefore lead to identifying areas of territorial specialization. By applying the model to Sardinian municipalities, this study shows that ESs are provided in bundles, and that some ESs compete with other, hence plan-making processes should carefully assess such trade-offs, as actions aiming at their enhancement can be detrimental to other ESs.
\end{abstract}

Keywords: ecosystem services; multifunctionality; territorial specialization; bundling; trade-offs

\section{Introduction}

As per the definition by the European Commission, a green infrastructure is 'a strategically planned network of natural and semi-natural areas [...] designed and managed to deliver a wide range of ecosystem services'. From a natural scientist's standpoint, this definition is problematic because human-centered, as residual naturalness in Europe is here thought of as something to be managed and planned to maintain ecosystem services (ESs), hence the goods and services provided by nature to humans. Moreover, 'a wide range' implies that several ESs can be delivered simultaneously; while some ESs are often jointly provided and intertwined [1], several studies show that some interrelationships are negative and result in trade-offs [2], especially as regards provisioning ESs. Therefore, by building on spatially explicit assessments of seven ESs carried out in previous research [3-6], this study aims at investigating multifunctionality, i.e., an area's capacity to provide simultaneously multiple ESs, so as to identify areas of territorial specialization on which planning policies can be grounded.

\section{Materials and methods}

\subsection{Study area}

With a size of $24,000 \mathrm{~km}^{2}$ and a population of around 1.6 million people, Sardinia is the second-largest Mediterranean island, here taken as a case study because its low residential density, low endowment of infrastructure, and persistence of traditional agricultural and farming practices have preserved a good level of naturalness, which is a prerequisite for the delivery of ESs. From an administrative perspective, Sardinia is an Italian autonomous region comprising four provinces and a metropolitan city (these represent the intermediate tier of government), in turns comprising a total of 377 municipalities. Municipalities are of outmost importance in the planning domain, in Italy, because they represent the lowest administrative tier of government in charge of land-use planning, whose provisions can greatly affect the supply of ESs. 


\subsection{Methodology}

The seven ESs here considered are as follows: habitat quality as potential nursery for species (QUHAB); global climate regulation (carbon sequestration and storage: CO2SEQ); local climate regulation (mitigation of land surface temperature REGTEMP); agricultural and forestry productivity (PRODAF); ecosystem-based potential recreation (POTRIC); intrinsic value of biodiversity for present and future generations (INTBIO); landscape quality, reflecting cultural identity and sense of place (QUPAES). The seven ESs were assessed and mapped (the reader can refer to [3-6] for an in-depth account), and their values normalized in the $0 \div 1$ range. Next, the mean normalized value was calculated for each Sardinian municipality ( $\mathrm{n}=377)$. Following Raudsepp-Hearne et al. [7], Turner et al. [8], Queiroz et al. [9], the analysis comprised three steps:

- for each ES, spatial patterns were analyzed by assessing spatial autocorrelation through Moran's I index; hotspots and coldspots of municipalities having statistically significant higher or lower values than their surrounding municipalities were identified through the Getis-Ord Gi* statistics;

- $\quad$ statistically significant (linear) correlations between each pair of ESs were assessed through Pearson's correlation coefficient;

- clusters comprising municipalities having a level of in-group similarity higher than their dissimilarities with respect to municipality not belonging to the group were spatially identified by applying first a principal component analysis (PCA), aimed at reducing redundancies due to the present of correlations, and next a cluster analysis through the k-means algorithm.

Except for the autocorrelation analysis, which was performed in GeoDa, version 1.6.7, the remaining operations were performed using ArcGIS®ESRI, version 10.7.

\section{Results}

Figure 1 provides an overview of the assessment of each ES at the municipal level; the autocorrelation analysis, carried out using the queen contiguity conceptualization, shows evidence of spatial agglomeration $(I>0)$ statistically significant and decreasing up to the fifth level of contiguity for all the ESs but for QUHAB, for which only the first two levels show evidence of autocorrelation. The results of the hotspot and coldspot analysis are shown in Figure 2, left-hand side, which puts in evidence that some parts of the island can be either hotspots or coldspots, depending on the ES at stake.

The Pearson coefficients (Table 1) show that 16 out of the 21 pairs of ESs are significantly and linearly correlated; negative correlations always concern PRODAF and CO2SEQ, which therefore compete with other ESs.

Table 1. Correlation analysis: Pearson coefficients (above-the-diagonal cells) and significance levels (below-the-diagonal cells: ${ }^{* * *}: \mathrm{p}<0.001$; $^{* *}: \mathrm{p}<0.01$; $^{*}: \mathrm{p}<0.05$ ). Blue and red shades highlight positive and negative correlations, respectively, while darker shades flag stronger correlations.

\begin{tabular}{ccccccc}
\hline INTBIO & 0.158 & 0.359 & 0.138 & -0.541 & 0.147 & 0.407 \\
\hline$* *$ & QUHAB & 0.320 & 0.173 & 0.080 & -0.036 & 0.033 \\
\hline$* * *$ & $* * *$ & POTRIC & 0.725 & -0.407 & -0.011 & 0.542 \\
\hline$* *$ & $* * *$ & $* * *$ & QUPAES & -0.095 & -0.314 & 0.486 \\
\hline$* * *$ & & $* * *$ & & PRODAF & -0.308 & -0.372 \\
\hline$* *$ & & & $* * *$ & $* * *$ & CO2SEQ & 0.155 \\
\hline$* * *$ & & $* * *$ & $* * *$ & $* * *$ & $* *$ & REGTEMP \\
\hline
\end{tabular}

Due to the presence of mutual correlation, the territory can be conceived of as a provider of bundles of ESs, rather than of single, independent, ESs, hence the PCA is helpful to reduce redundancies. The PCA shows that approximately $93 \%$ of the variance can be explained through four new axes, or around $97 \%$ through five axes, which represent as 
many combinations of the seven ESs. Therefore, the k-means algorithm was run seeking out for five clusters, whose spatial layout is shown in Figure 2, right-hand side, together with the spider diagrams that provide the mean value of each ES in each group.

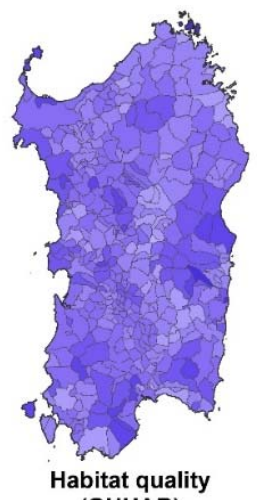
(QUHAB)

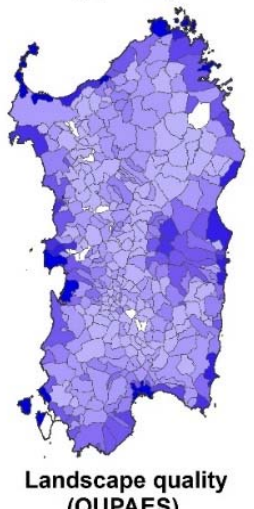
(QUPAES)

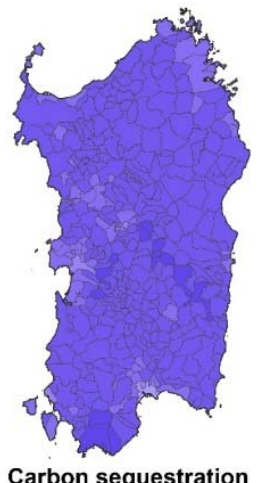

Carbon sequestration
and storage (CO2SEQ)

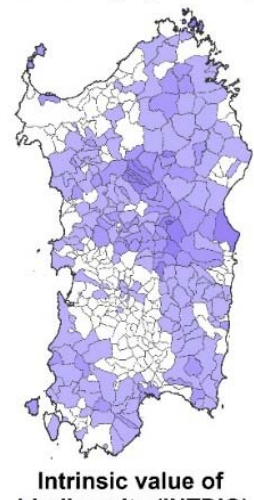

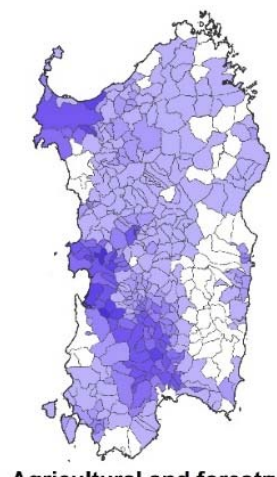

Agricultural and forestry productivity (PRODAF)

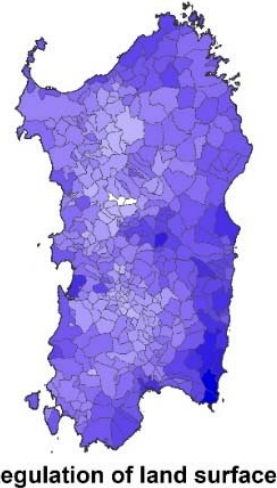

temperature (REGTEMP)

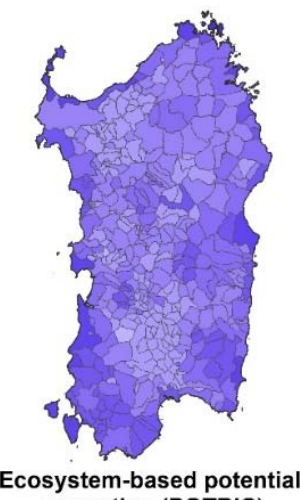

recreation (POTRIC)

Figure 1. Mean ES normalized values at the municipal level.
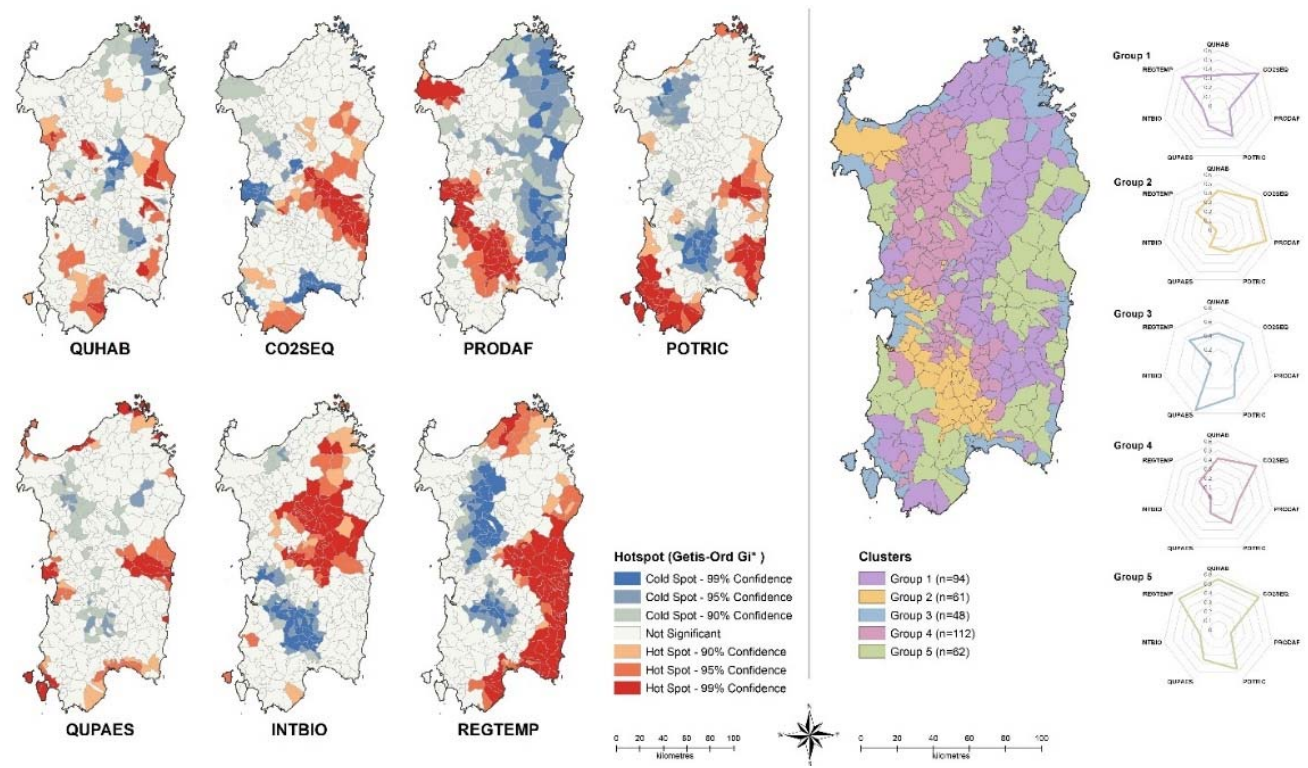

Figure 2. Hotspots and coldspots of mean ES values, municipal level (left), and results from the cluster analysis (right).

As Figure 2 shows, five municipal clusters can be identified; municipalities in each cluster share common features in terms of bundles of ESs provided, and they also share some distinctive environmental and socio-economic characteristics. Group 3, where QUPAES and POTRIC dominate, comprises almost exclusively coastal municipalities, 
whose economies rely on tourism, and whose urbanization levels are generally higher than those within the rest of the island. Group 2, having high values of both PRODAF and CO2SEQ, corresponds to the island's main plains, hosting intensive agriculture and farming that yield comparatively high incomes with respect to Sardinian standards. Groups 1 and 4, both showing high values of CO2SEQ, differ as regards PRODAF (low in 1 and high in 4) and REGTEMP (high in 4 and low in 1); while they both comprise inner and sparsely populated municipalities, they differ as for the morphology, which is gentler in group 4, and the vegetation, which in group 4 is richer in steppe and other herbaceous vegetation and pastures. Finally, group 5 comprises municipalities having high values of all ESs except PRODAF; it includes the island's main mountain areas, whose landscapes are marked by maquis and forests, the greatest providers of ESs in Sardinia.

\section{Conclusions}

The analysis of bundles of ES provision at the municipal levels unveils spatial patterns reflecting both ecological and socio-economic patterns. A case can therefore be made for the existence of a territorial specialization [9] that should be accounted for within landuse plans, whose actions can either enhance or degrade the supply of some ESs. Awareness should be raised on the fact that planning provisions aimed at fostering some ESs (first and foremost, agricultural productivity) are often detrimental to the maintenance of other ESs, as, for instance, regulation and cultural ESs [10]; thus, such trade-offs call for careful ex-ante assessments in plan-making processes. Future research directions concern the consideration of a larger number of ESs, through which sensitivity and stability of the clusters could be better assessed, and the inclusion of socio-economic control variables.

Funding: This research received no external funding.

Acknowledgments: This study has been carried out in the framework of the Research projects "Paesaggi rurali della Sardegna: pianificazione di infrastrutture verdi e blu e di reti territoriali complesse" (funded by the Autonomous Region of Sardinia, 2017 call for "Basic research projects" as per regional law 7/2007), and "Investigating the relationships between knowledge-building and design and decision-making in spatial planning with geodesign" (funded by Fondazione di Sardegna, 2018 call).

Conflicts of Interest: The author declares no conflict of interest.

\section{References}

1. Bennett, E.M., Peterson, G.D., Gordon, L.J. Understanding relationships among multiple ecosystem services. Ecology Letters 2009, 12, 1394-1404.

2. Madureira, H., Andresen, T. Planning for multifunctional urban green infrastructures: Promises and challenges. Urban Design International 2014, 19, 38-49.

3. Lai, S., Leone, F. A methodological approach to identify a multifunctional green infrastructure at the regional scale. A case study from Sardinia, Italy. Urbanistica Informazioni 2017, 272 s.i., 836-840.

4. Floris, M. I servizi ecosistemici nella pianificazione spaziale come strumenti interpretativi per la definizione di tassonomie territoriali innovative. PhD thesis, University of Cagliari, Italy, March $6^{\text {th }}, 2020$.

5. Lai, S., Leone, F., Zoppi, C. Spatial distribution of surface temperature and land cover: A study concerning Sardinia, Italy. Sustainability 2020, 12, art. no. 3186.

6. Lai, S., Isola, F., Leone, F., Zoppi, C. Assessing the potential of green infrastructure to mitigate hydro-geological hazard. TeMA - Journal of Land Use, Mobility and Environment 2021, s.i. 1, 109-133.

7. Raudsepp-Hearne, C., Peterson, G.D., Bennett, E.M. Ecosystem service bundles for analyzing tradeoffs in diverse landscapes. Proceedings of the National Academy of Sciences 2010, 107(11), 5242-5247.

8. Turner, K.G., Odgaard, M.V., Bøcher, P.K., Dalgaard, T., Svenning, J.-C. Bundling ecosystem services in Denmark: Tradeoffs and synergies in a cultural landscape. Landscape and Urban Planning 2014, 125, 89-104.

9. Queiroz, C., Meacham, M., Richter, K., Norström, A.V., Andersson, E., Norberg J., Peterson, G. Mapping bundles of ecosystem services reveals distinct types of multifunctionality within a Swedish landscape. AMBIO 2015, 44, 89-101.

10. Martín-López, B., Iniesta-Arandia, I., García-Llorente, M., Palomo, I., Casado-Arzuaga, I., García Del Amo, G., GómezBaggethun, E., Oteros-Rozas, E., Palacios-Agundez, I., Willaarts, B., González, J.A., Santos-Martín, F., Onaindia, M., LópezSantiago, C., Montes, C. Uncovering ecosystem service bundles through social preferences. Plos One 2012, 7(6), art. no. e38970. 